\title{
In Between Research Cultures - The State of Digital Humanities in Finland
}

\author{
Inés Matres \\ University of Helsinki \\ ines.matres@helsinki.fi \\ https://orcid.org/0000-0002-4544-4946 \\ Mila Oiva \\ University of Turku \\ milaoiv@utu.fi \\ https://orcid.org/0000-0002-5241-7436

\section{Mikko Tolonen} \\ University of Helsinki \\ mikko.tolonen@helsinki.fi \\ https://orcid.org/0000-0003-2892-8911
}

Digital humanities (DH) as a research field has been developing rapidly in Finland during the past few years, mainly due to increased funding and profiling activities. Although these infrastructural developments have created (smaller and larger) centres, hubs and clusters related directly or indirectly to digital humanities, the future of Finnish research in this area depends on how the various scholarly and memory organisations, as well as individual scholars, succeed in joining forces. The overall argument in this paper is that digital humanities needs to establish its identity and to create a new space among research cultures with varying characteristics tackling a multitude of problems, and that this can only be achieved through national collaboration and the joint exploitation of the strengths of existing DH hubs. The article sets out a roadmap to this end, providing a detailed discussion of various developments in digital humanities, and analysing different possibilities in the international context. It is based on a survey conducted in 2016 among Finnish scholars in the fields of humanities and the social sciences, an analysis of existing infrastructures, and interviews with $\mathrm{DH}$ scholars involved with international top-level DH centres. The focus in the latter part of the article is on these interviews, and on the lessons learned abroad from which the Finnish DH community could benefit. We conclude with a strong call for collaboration to facilitate the further development of the DH field in Finland in response to international competition.

Asiasanat: digital humanities; research infrastructures; digital research practices; Finland; data; collaboration; open science

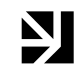


Digital humanities (DH) is a scholarly field situated in-between divergent research cultures and approaches. It incorporates both humanities research based on computer-assisted methods, and the humanities-based study of digital cultures. Finland is currently a fertile ground for such research. Finnish funding agencies have been emphasising digital humanities in their calls for research during the past few years, and $\mathrm{DH}$ research has been shaped by evolving organisational structures. Some of this development has been effected through different profiling actions (that are also political in nature) implemented at different universities based on divergent strategies. From the perspective of digital humanities, this has been a welcome development on the one hand, because more resources have been directed towards this field. At the same time, the profiling of research also creates specific tensions given the novelty of the instruments and the very rapid pace of change. Throughout the article we discuss this aspect of digital humanities within the larger framework of recent developments in Social Sciences and Humanities (SSH) research.

We have identified at least the following four issues that need to be resolved over the coming years if digital humanities is to be successful: 1) currently, and for various reasons, there is clear resistance to change in traditional SSH scholarship, specifically related to $\mathrm{DH}$ and the implementation of new methods and practices; 2) methodological development should be humanities-driven; 3) although the emphasis has to be on the development of SSH methodology, the research questions should be the primary focus in $\mathrm{DH}$; 4) the different infrastructural developments in SSH research cannot become a zero-sum game, and there is a need for genuine national collaboration. The main reason for the resistance to change is that $\mathrm{SSH}$ research is lagging behind both in the implementation of new methods and in the development of relevant competences. This will change only through research and training, in other words simply by demonstrating enough convincing findings in $\mathrm{DH}$ research to prove that it is worthwhile. We offer a roadmap for this in the form of a detailed discussion of developments in $\mathrm{DH}$ and an analysis of the various options in an international context. The idea is not to resolve all these issues, but to offer an evidence-based analysis that will function as a basis for further discussion ${ }^{1}$.

1 The primary writing responsibility in this collaborative article was divided as follows: Tolonen was responsible for writing the "Digital Humanities and Finland" section, Matres for the "Survey on digital research practices in Finland" and "Ways of doing research digitally" sections, Oiva for the "Digital push for change" section, and everyone for the "Conclusions". All the authors contributed to and influenced the final version of the article. We would like to thank the two anonymous authors for their critical comments that helped considerably to improve this paper during the review process. 


\section{A survey of digital research practices in Finland}

Digital humanities $(\mathrm{DH})$ is a broad area of study that is defined differently depending on the context and the intended application of the concept. It applies both to research in the humanities that utilises computer-assisted methods, and to the study of digital cultures. On the infrastructural level it is generally used as an umbrella concept incorporating everything from the study of digitisation to the use of computational methods. Perhaps most typically, however, DH refers to the use of data science within the realm of SSH research ${ }^{2}$.

To uncover the state of digital research practices and to assess how Finnish research in the humanities benefits from the digital age and the opportunities it offers, Inés Matres (under the supervision of Mikko Tolonen) conducted a survey in 2016 (Matres, 2016) ${ }^{3}$. The survey questionnaire focused on practices and needs during the data-collecting cycle: discovering, organising, analysing and publishing (Puhl et al., 2015). This survey originated in the DARIAH Digital Methods and Practices Observatory (DiMPO), which collected data from 10 European countries. The main motivations for carrying it out were to contribute data to the international survey (Dallas et al., 2017) and to identify national trends and priorities for developing the recently created Helsinki Centre for Digital Humanities. We distributed the survey to the eight universities offering doctoral programmes in the Humanities. Post-doctoral, junior and senior researchers from humanities and the arts in the three universities in the Helsinki region were also invited to participate as a smaller sample representing the later stages in the researcher's career. We received a total of 239 responses, mainly from doctoral students $(35 \%, r=83)$, followed by post-doctoral and junior researchers $(26 \%, r=62)$ and, finally, a similar number of Master's-level students and senior researchers $(14-15 \%, r=33-35)$. Three humanities disciplines participated more actively in this survey: linguists $(24 \%, r=57)$, historians $(19 \%, r=45)$ and cultural researchers $(13 \%, r=31)$. Interestingly, at least a third of the respondents $(36 \%, r=86)$ also identified with a second field of research, inside or outside traditional humanities subjects (e.g. media studies and education).

Although no extensive report on the data collected in Europe has been published so far, three main findings from the Finnish sample give some indication about the state of digital research practice in Finland.

On SSH research and the Horizon 2020 (EU framework programme for research and innovation), see: https://ec.europa.eu/programmes/horizon2020/en/area/social-scienceshumanities This survey was undertaken by the University of Helsinki, in October-November 2016. 


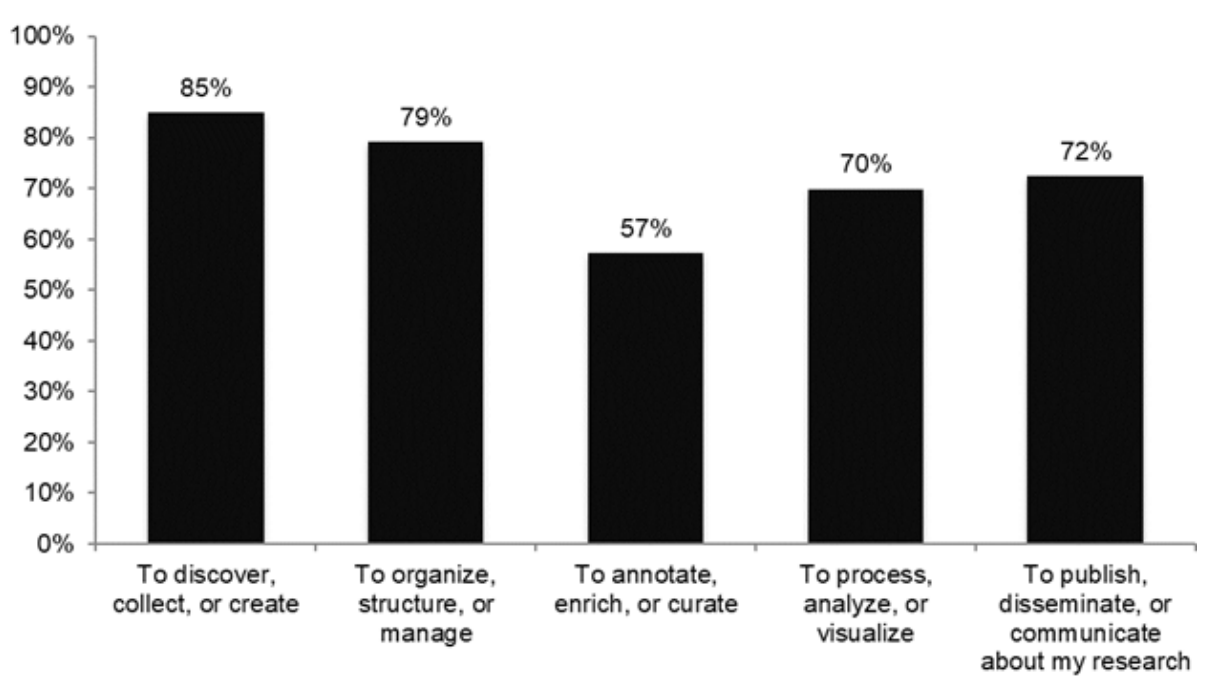

Figure 1: For what purpose do you use or are interested in using digital tools and research methods? $(\mathrm{N}=239)$

First, digital materials are already used more extensively than printed or otherwise analogue data. Although books are still read as much in print as digitally, 70 per cent of the respondents reported accessing archival holdings from a digital device, whereas only 36 per cent relied on archive visits or printed material. Moreover, seven in ten researchers engaged in digital research practices. However, as the Figure 1 shows, this was more common during the early stages of the research for discovering and acquiring material than in later stages of data analysis and communicating results. In terms of disseminating research findings, most humanists still aim at academic publications, and less than a quarter $(21 \%, r=50)$ consider other digital outcomes such as repositories, tools or websites.

Second, a diversity of data is used for research purposes. As shown in the Figure 2, items beyond scholarly publications, literary works and digitised archival collections are listed. These resources, organised in a word cloud by number of mentions among survey respondents, show how humanists make use of various originally digital data, including social-media content, databases, and data generated during participative activities such as audio recordings or online surveys.

Third, most respondents $(93.7 \%, r=224)$ considered better accessibility to resources the most important requirement for doing research in the digital age. They specifically mentioned the need for the further digitisation of research sources, and for them to be attached to open licenses and referencing guidelines 


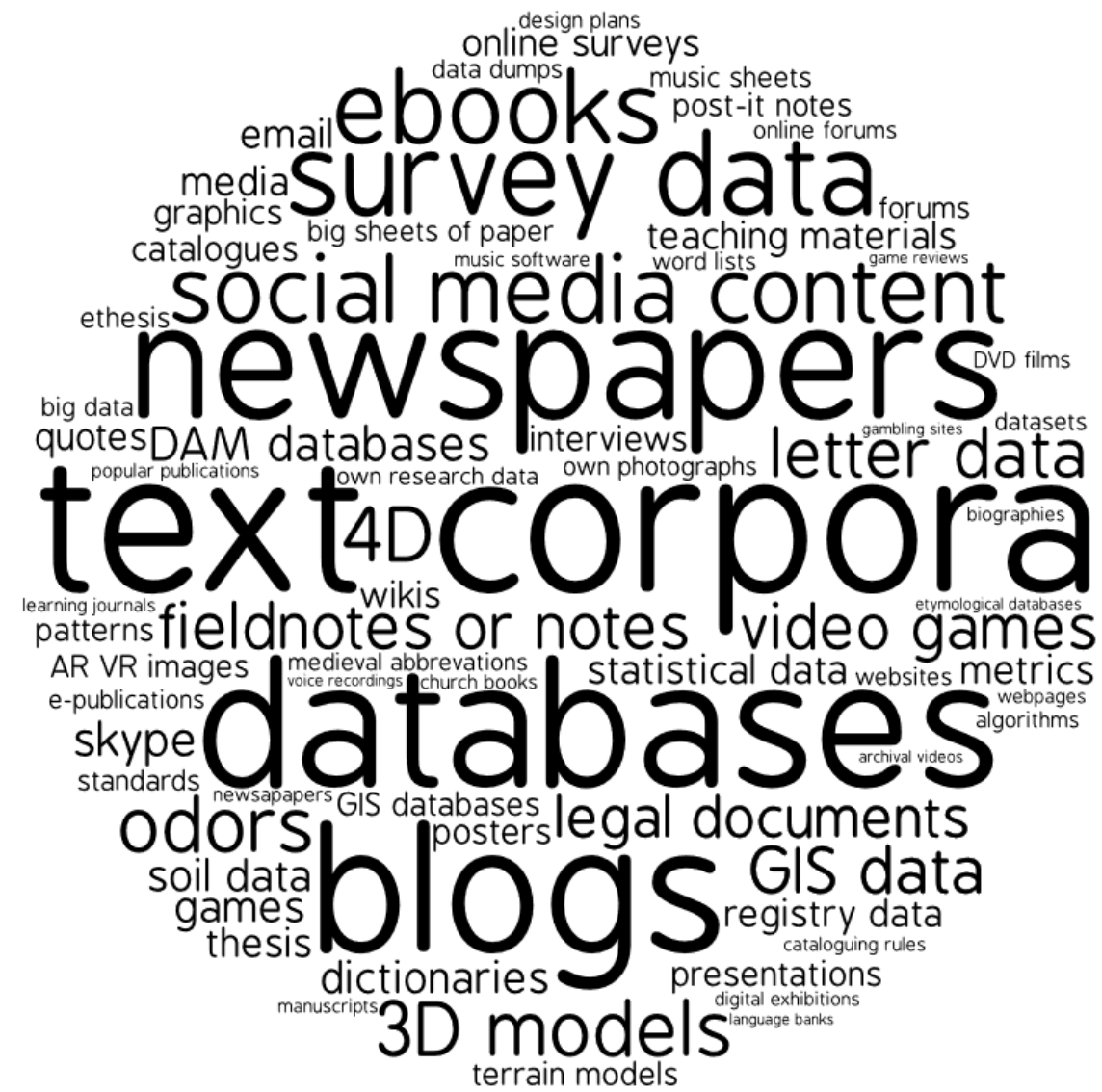

Figure 2: Word cloud of digital resources used by the respondents ( $r=66)$ : "In addition to scholarly publications, published literature, digitised archival collections, manuscripts, images, videos, audios and maps, what other digital resources are accessed in your research?" 
as essential for their re-use in scientific contexts.

The survey included an option for respondents to freely express their unfulfilled needs regarding the digital infrastructure. Only two out of ten gave feedback $(r=47)$. Nevertheless, we were able to highlight three challenges: learning to handle big data, the assumption that online content is available to researchers, and trusting that relevant data is already in digital form. Accessing digital research data may be technically challenging and could require special knowledge and competence. The development of digital humanities in university curricula is one solution to this challenge. However, the respondents found support in other disciplines: social-science researchers used methods traditionally associated with corpus linguistics such as text mining and topic modelling, for example. Furthermore, digital resources available online could potentially come up against ethical and legal barriers. This is the case with social-media content, a popular source of research data, which entails reassuring providers about the ethical treatment of their data. Finally, expecting research data to be available online could also make researchers less willing to seek assistance professionals in archives, special collections or museums: 60 per cent of the survey respondents seldom or never did this. Researching or even digitising collections that are not yet digitised could result in fruitful collaboration with the cultural heritage or collecting institution holding the materials.

In sum, on the one hand digital practices in the humanities in Finland enable scholars to explore interdisciplinary interests, and to make use of diverse digital data: from digitised collections to born-digital data. On the other hand, digital data poses challenges related to access, data management, and ethical referencing and use.

This survey targeted researchers from a wide range of disciplines. In the following section, therefore, we investigate practices and methods that are characteristic of digital humanities, first with reference to HELDIG and subsequently focusing on five individual researchers involved in $\mathrm{DH}$ projects related to their research and discipline, their acquisition and treatment of digital data, and their use of digital methods ${ }^{4}$. Finally, we consider the international DH scene to better understand the particularities and perspectives of DH in Finland. ber 2016 and November 2017, and lasted from 30 minutes to one hour. 


\section{Digital humanities and infrastructural developments in Finland}

As the survey indicates, the use of digital archives and basic computational tools to access and acquire digital research resources (such as search engines and the most common graphic user interfaces) is becoming a matter of everyday practice. Thus, for something to be considered digital humanities requires the more extensive use of computational methods. This, in turn, means that digital humanities tends to be a collaborative effort combining the expertise of SSH researchers and data scientists. In addition to this computing aspect, the Academy of Finland stated in their DH call launched in 2015 that "one aspect of the programme is to examine digitalisation as a cultural and social phenomenon". According to this umbrella-type definition, digital humanities concerns not only the use of data science in SSH research, but also the study of the digital world. The University of Helsinki has followed this principle in establishing HELDIG, its centre for digital humanities. ${ }^{5}$

Although the trend in defining digital humanities is to put the emphasis on data science in the research, the aspect of change in the research culture within the humanities should also be emphasised. We discuss collaboration in digital humanities in more detail below, but we should remind the reader that humanities scholarship tends to be seen as centred on single-author monographs (Dallas et al., 2017). DH is certainly changing this in that genuine collaboration between scholars from different fields often results in shared authorship (this is also made clear in the interviews with foreign $\mathrm{DH}$ scholars discussed below). At the same time, one should be mindful of what humanities scholarship is all about. DH research cannot be about "playing with data", and it cannot be outsourced to researchers who have no, or very limited, humanities training. ${ }^{6}$ When the interest of knowledge lies within the humanities, the research questions should dominate the methodology. This is by no means easy, and it is somewhat safe to say that the transformative effect of digital humanities on SSH research in general has been slower than most eager enthusiasts would perhaps have anticipated. Although there is a clear need to remain critical of $\mathrm{DH}$ (as with any field of science), there is a separate, somewhat unfounded dismissal of it that is a question of misunderstanding rather than being critical.

For more on the Academy of Finland DIGIHUM programme, see: http://www.aka.fi/en/ research-and-science-policy/academy-programmes/current-programmes/digihum/; on HELDIG, see https://www.helsinki.fi/en/helsinki-centre-for-digital-humanities On the clashes between DH work and humanities scholarship see the classic exchange in Allen et al. (2010) and Leca-Tsiomis (2013). On the more successful use of computational methods to classic historical questions see Ahnert \& Ahnert (2015). 
Negative outbursts directed at digital humanities have broken out several times in different contexts. ${ }^{7}$ Although DH certainly should not be dismissed out of hand, the main reason for remaining sceptical about it is the lack of clear and demonstrative cases in which the use of new methods has genuinely made an impact on traditional scholarship. ${ }^{8}$ One interesting question about the nature of DH concerns how archaeology fits within its framework. The early adoption of $3 \mathrm{D}$ and digital technologies for reconstruction has put archaeology at the forefront with regard to the use of digital methods in the humanities. However, the relationship between archaeology and $\mathrm{DH}$ remains ambivalent at many universities. ${ }^{9}$

$\mathrm{DH}$ is also concerned with communities, communication and the critique of technocentrism. We discuss scholarly communication in more detail below, but we should point out here that new communication channels such as Slack ${ }^{10}$ are routinely changing scholarly interaction on many different levels. At the same time, some $\mathrm{DH}$ communities are founded on new ways of communicating, one example being a movement called postcolonial digital humanities. ${ }^{11} \mathrm{~A}$ major dimension of $\mathrm{DH}$ is the critical evaluation of technology and society, which is quite different from existing technocratic dreams of finally making the humanities "useful" (on the critical evaluation of technology and society from the perspective of DH, cf. Bassett, 2015). The discussion in $\mathrm{DH}$ communities about the changing landscape of humanities has focused on the different waves of DH. According to the The Digital Humanities Manifesto 2.o, "the first wave of digital humanities work was quantitative, mobilizing the search and retrieval powers of the database, automating corpus linguistics, stacking hypercards in critical arrays. The second wave is qualitative, interpretive, experiential,

On the Finnish debate on the development of a $\mathrm{DH}$ infrastructure at the University of Helsinki, see Hankamäki (2017) and Mustajoki's (2017) response; for an excellent response to the often-repeated claims about the uselessness of DH, see Laura Mandell's recent post http://idhmc.tamu.edu/node/191 answering Timothy Brennan, The DigitalHumanities Bust. After a decade of investment and hype, what has the field accomplished? Not much. The Chronicle of Higher Education. October 15, 2017 https://www. chronicle. com/article/The-Digital-Humanities-Bust/241424.

For a recent discussion about this with respect to digital history, see https://rrchnm.org/ wordpress/wp-content/uploads/2017/11/digital-history-and-argument. RRCHNM.pdf Archaeology features prominently below digital humanities at the University of Oxford, for example: https://digital.humanities.ox.ac.uk/divisions/archaeology The case is not the same elsewhere, not least because different computational methods (e.g., $3 \mathrm{D}$ scanning) have been used in archaeology for some time, whereas digital humanities tends to be labelled a still-emerging field within traditional (and often text-based) humanities. On Slack and DH, cf: http://blogs.lse.ac.uk/impactofsocialsciences/2016/07/13/ using-slack-to-support-a-geographically-dispersed-community/ http://dhpoco.org/ We are grateful to Eetu Mäkelä for this observation. 


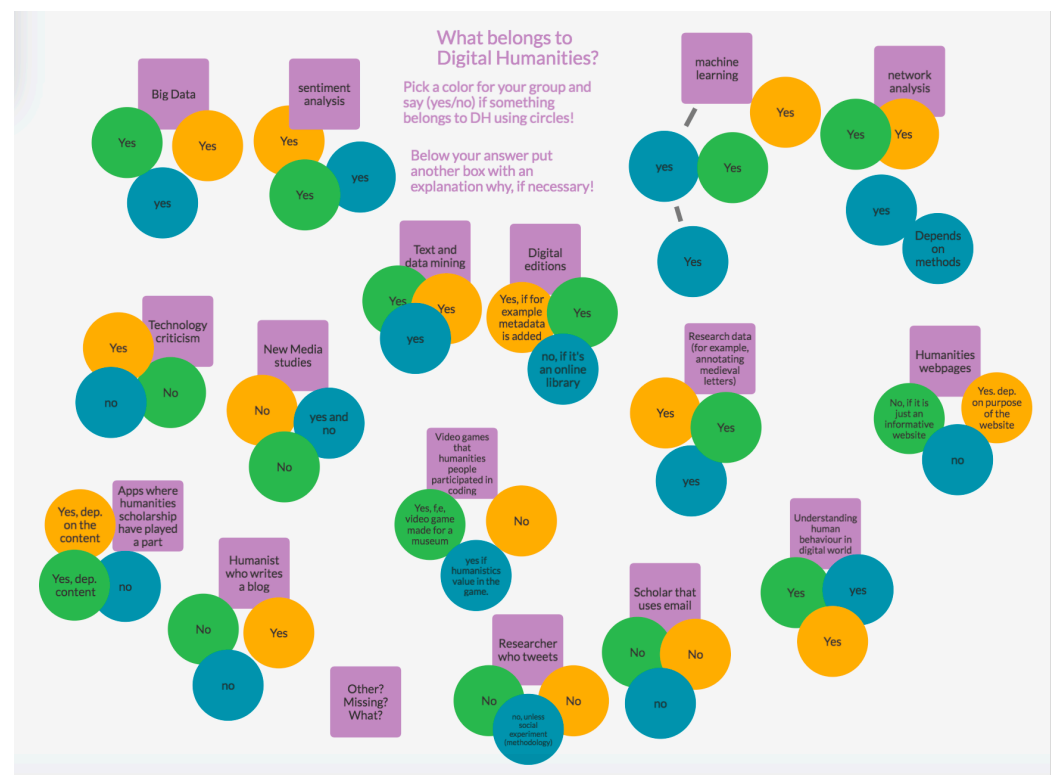

Figure 3: What belongs to digital humanities? This was a task undertaken by three groups of students in the Introduction to Digital Humanities course in Autumn 2017 (taught by Mikko Tolonen at the University of Helsinki), illustrating DH as a combination of SSH research and data science.

emotive, generative in character. It harnesses digital toolkits in the service of the Humanities' core methodological strengths: attention to complexity, medium specificity, historical context, analytical depth, critique and interpretation." ${ }^{2}$ Some theorists are already talking about the third wave of $\mathrm{DH}$, although it is not yet evident that the first wave has quite hit the shore in terms of showing that quantitative research is indeed changing humanities research traditions (for a suggestion about the need for post-digital humanities, see Berry, 2014). One justified perspective is that, on the general level, digital humanities should not be directly compared to traditional humanities scholarship because as a multidisciplinary undertaking it also incorporates technical elements and methods that are not present in traditional research in the social sciences and humanities.

Other major aspects of digital humanities include the question of the space in which SSH research is conducted and the ways and mediums in which it is done (Svensson, 2015). It is also worth noting that media studies and digital art dominate the discussion about digital humanities in many North American universities and liberal-arts colleges, whereas students at the University of 
Helsinki might feel that new media studies do not belong to $\mathrm{DH}$ at all (see Figure 3). One explanation for these differences in emphasis may lie in the way different institutions of knowledge creation (and the teaching within them) have been formed. In the Helsinki region, for example, research in humanities and the social sciences at the University of Helsinki has traditionally focused on interpreting and understanding textual materials, which is also reflected in the way that humanities students understand their own field. Digital art and new media studies are increasingly being taught at Aalto University. ${ }^{13}$ This institutional and, at the same time, somewhat arbitrary division that has its own logic and history creates a further need for institutional collaboration. Fortunately, interaction between the humanities faculty and UniArts (University of the Arts Helsinki) is showing signs of emergence. ${ }^{14}$ In any case, although all teaching institutions operating under the umbrella of $\mathrm{DH}$ (whether it be from a humanities, a media or an arts perspective) should emphasise the diversity of cultural heritage: humanities scholarship in particular cannot be based exclusively on textual sources. It is therefore justified to insist that when it comes to cultural heritage, $\mathrm{DH}$ scholarship has to reflect (in theory and methods) the processes and results of digitalisation.

Digital Humanities is also about reassembling humanities infrastructures. This entails bringing different stakeholders together in close collaboration that facilitates the creation of something new by digital means. A major factor in $\mathrm{SSH}$ research has always been the presence of libraries and archives (Sula, 2013). Collaboration among memory organisations, universities and researchers is all the more important from a DH perspective because data processing and tool development cannot be effective without the involvement of all stakeholders. These stakeholders include individual researchers, research groups, networks such as Clarin ${ }^{15}$ (European Research Infrastructure for Language Resources and Technology) and Dariah ${ }^{16}$ (a pan-European infrastructure for arts and humanities scholars working with computational methods) and, of course, national and private memory organisations. ${ }^{17}$ In the Helsinki region, the National Library of Finland and the University Library of Helsinki have made commendable efforts to enhance DH collaboration with researchers. The National Archives of Finland are involved in a READ project that could change the way in which

\footnotetext{
13 See, for example, https://medialab.aalto.fi/

14 http://www.uniarts.fi/tapahtumat/ke-23112016-2036/art-technology-symposium

15 https://www.clarin.eu/

16 https://www.dariah.eu/

17 On Fin-Clarin and links to the language bank of Finland and its other operations, see https://kitwiki.csc.fi/twiki/bin/view/FinCLARIN/KielipankkiFrontpage
} 
manuscripts are transformed into a digital and machine-readable form. ${ }^{18}$ The Finnish Literature Society (SKS) and the Society of Swedish Literature in Finland (SLS) could also be called global frontrunners in digital editing. ${ }^{19}$

The $\mathrm{DH}$ community in Finland is scattered among different universities focusing on various aspects of the phenomenon. Geographically, DH research is carried out in a few strong centres and by scholars working more independently in different universities. The study of the digital culture has a longer history in the Finnish humanities landscape. The early development phase in the late 1990s was focused in Turku (and Pori) as well as Jyväskylä (Haverinen \& Suominen, 2015; Järvinen, 1999; Suominen, 2013). A particularly extensive infrastructural development was the establishment of the HELDIG Centre for Digital Humanities at the University of Helsinki in collaboration with Aalto University (Hyvönen, 2017). This profiling action was funded mainly through the Academy of Finland and the University of Helsinki. One crucial goal of HELDIG is to bring different stakeholders together. It should therefore not restrict its focus to the Helsinki region, but should function as the beacon of digital humanities for all of Finland and the Nordic countries. The other Finnish Universities are also taking clear actions to reshape digital SSH research. The University of Turku has been one of the forerunners in computational linguistics applications in Finnish for some time, attributable to the efforts of scholars at the Department of Information Technology, and to their recent collaboration with historians, for example. ${ }^{20}$ At the University of Tampere, the School of Information Sciences (recently divided into two different faculties) ${ }^{21}$ has been producing very good work for many years, much of which clearly falls within the range of digital humanities. It hosts one of the most extensive sources of quantitative and qualitative data in digital format for social research in Finland. The University of Eastern Finland has been strong on GIS and different mapbased applications of $\mathrm{DH}$ at the Department of Geographical and Historical studies. ${ }^{22}$ Instead of a traditional university library, Jyväskylä boasts an Open Science Centre that serves digital humanities. ${ }^{23}$ Digitalia, in the Mikkeli region, is making an important contribution to advancing $\mathrm{DH}$ nationally ${ }^{24}$, and the

https://wWw. arkisto.fi/en/the-national-archives/projects-2/READ-4

For an example of SKS's efforts, see Elias Lönnrot's letters project in which commendable open-science principles were implemented from the beginning http://lonnrot.finlit. fi/omeka/. For an example of SLS's undertakings, see the award-winning project on Zacharias Topelius's writings http://www. topelius.fi/.

https://turkunlp.github.io/

http://www.uta.fi/sis/en/faculty/index.html

https://www.uef.fi/en/web/geohistoria

https://osc.jyu.fi/en

https://www.xamk.fi/tutkimus-ja-kehitystoiminta/digitalia/ 
University of Oulu hosted the annual ADHO digital humanities conference in 2008..$^{25}$ The Aalto University History of Industrialization and Innovation (HIIVA) group has been studying the status of digital history research in Finland (Paju, 2016), and aims at further facilitating this development. These are just a few examples of longer-term efforts to support digital humanities in Finland.

Strong DH centres may hold the key to the development of the DH field in Finland, given their potential to strengthen international and national collaboration. The core idea behind Dariah is to support digital research as well as the teaching of relevant research methods, which is precisely what is needed in Finland to exploit the collaboration potential of digital humanities. One possibility would be to support Finland's joining both Dariah and Clarin. The University of Helsinki and Aalto University are already cooperating partners with Dariah, but Finland is not yet a member state in the infrastructure. HELDIG is also representing Finland in Dariah's European Research Infrastructure Consortium's (ERIC) Sustainability Redefined Horizon 2020 project (DESIR), the aim of which is to pave the way for becoming a Dariah member state. ${ }^{26}$ Application for membership has to be a national initiative, and Dariah would need first to have its place on the Finnish infrastructure roadmap. ${ }^{27}$ Joining Dariah would also benefit individual researchers in their EU funding applications. After Horizon 2020, in a new EU-wide framework, it will be all the more important for the Finnish research infrastructure to support both Clarin and Dariah, which are the landmark ERIC projects in the humanities. European developments will most likely be such that even more relevance in individual applications (such as to the ERC) should be assigned to infrastructure that supports the research. Given the amount of money and effort the EU has put into this framework project, it is quite obvious that being national members in these landmark endeavours will be of significant help to individual applicants in securing backing. Dariah also creates a natural channel for new forms of Nordic collaboration within the digital realm. There has been ongoing Dariah Nordic Hub collaboration since 2015, with funds secured for compiling a report on shared Nordic teaching needs in digital humanities (the NEIC project). ${ }^{28}$ Finnish researchers have also been active in the Nordic Digital Humanities organisation. ${ }^{29}$ Its annual

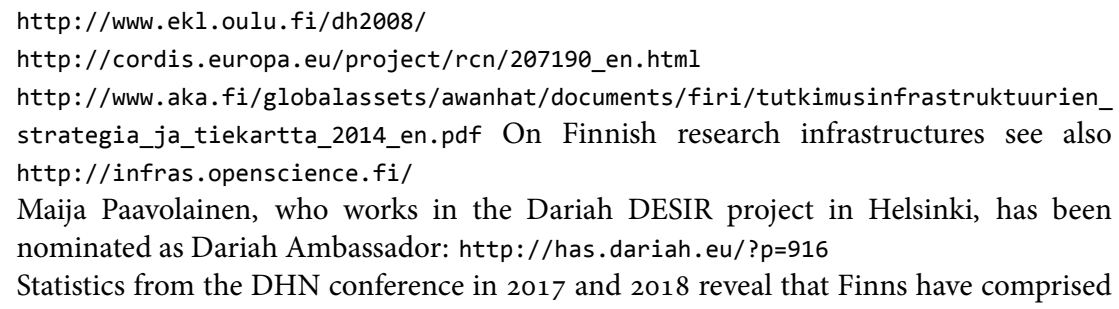
strategia_ja_tiekartta_2014_en.pdf On Finnish research infrastructures see also http://infras.openscience.fi/

Maija Paavolainen, who works in the Dariah DESIR project in Helsinki, has been nominated as Dariah Ambassador: http://has.dariah.eu/?p=916 Statistics from the DHN conference in 2017 and 2018 reveal that Finns have comprised 
conference was held in March 2018 in Helsinki. ${ }^{30}$

Different humanities disciplines have divergent science-historical backgrounds, which leads to varying approaches and levels of preparedness to utilise digital research methods. Despite the differences there are no strong tensions between humanities scholars utilising such methods. As one manifestation of fruitful inter-humanities and social-sciences collaboration, the University of Helsinki has recently recruited several tenure-track professors in digital humanities to join HELDIG. Fields ranging from "Legal Research on Digitization" to "Russian Big Data Methodologies" and "Religion and the Digital World" are represented in this $\mathrm{DH}$ centre, showing how digital humanities extends well beyond the use of data science in SSH research. Computer science at the University of Helsinki is also contributing with its new emphasis on data science. ${ }^{31}$ Funding for HELDIG comes from two different sources, the Academy of Finland's profiling action in 2016 and investments made by the University itself. ${ }^{32}$ The former is meant to be competitive funding aimed at strengthening university research profiles, which goes hand in hand with the rather dramatic and rapid change that is taking place in the Finnish educational landscape. Given the continuously increasing pace and scale there is also a heightened sense of uncertainty and instability among researchers, which applies to both digital and traditional humanities as well as to other fields of science. This also creates tension among $\mathrm{DH}$ practitioners because it is not evident that efforts to create something new will bear fruit in the long run. The Faculty of Arts at the University of Helsinki has reshaped its departmental structure in 2018, which has resulted in the formation of the new Department of Digital Humanities (which includes language technology, phonetics, cognitive

by far the largest Nordic group submitting papers to the conference (followed by Swedish and Danish researchers). We would like to thank Eetu Mäkelä for providing us with this information.

https://www.helsinki.fi/en/helsinki-centre-for-digital-humanities/dhn-2018 On DHN in general, see: http://dig-hum-nord.eu/

31 One important component is the establishment of the Helsinki Centre for Data Science (HiDATA), see: https://www.helsinki.fi/en/programmes/master/data-science/hidatakick-off-1-dec-2017. A further significant development is the new Master's Programme in Data Science, in which digital humanities also features as one field of application: https://www. helsinki.fi/en/masters-programme-in-data-science-masterof-science-2-years/1.2.246.562.17.85725809561 There is also strengthened collaboration between Computer Science and Digital Humanities in the form of a recently funded Horizon 2020 project (NewsEye - A Digital Investigator for Historical Newspapers (EU H2020, 2018-2021)). See also, FCAI: https://fcai.squarespace.com/research/ 
science, computational history and DH infrastructures, including Fin-Clarin). This will give an opportunity to profile these varied fields of knowledge under digital humanities and to find common ground between them. Obviously, these rather recent administrative developments are backed up to some extent by previously established operations. The DH research seminar at the University of Helsinki has been running for a few years ${ }^{33}$, digital humanities is taught as a minor-subject study block in the Faculty of Arts, some research groups have been developing their approaches for decades, ${ }^{34}$ and the first doctoral students specifically focusing on digital humanities at the Faculty of Arts were admitted in 2014 (Sinnemäki \& Tolonen, 2015). Language technology has, of course, been taught at the University of Helsinki since 1987.35

There is nevertheless still a need to strengthen national DH collaboration to create better and more equal opportunities for all scholars interested in contributing to the research in different universities across Finland. One example of such attempts is the Digital History Research Methods Roadshow ${ }^{36}$, which toured Finnish university history departments giving a one-day introductory seminar on DH research methods, and getting interested scholars to talk to each other. This was the first step towards strengthening national DH collaboration in the field of history, which could spread and be developed further.

In addition to fostering collaboration among disciplines and universities there would be even more room to develop cooperative ventures with other organisations in Finland. Many instances of the open-science movement are fundamental in advancing digital scholarship, for example. Open Knowledge Finland (OKFfi) and its Open Science working group were given an award by the Ministry of Culture and Education earlier this year for advancing scientific publishing, which is of course highly relevant to $\mathrm{DH}$ as well as to other fields of science. ${ }^{37}$ From the perspective of computing infrastructure, Finland with its strong ICT background is in many ways an ideal country in which to take DH research and its application to the next level. To our knowledge, for example, the data support and opportunities to use high-performance computing (HPC) offered by the CSC (the Finnish IT Center for Science), which are also accessible

36 The Roadshow was organised by the Aalto University History of Industrialization and Innovation group in January-February 2018. 
to SSH researchers, are unique in the world, including in the other Nordic countries..$^{38}$ There are also many existing grassroots groups enabling researchers with similar interests to find each other. ${ }^{39}$ Thus, it is safe to say that Finland is a fertile ground for digital humanities, especially if the next steps are taken to serve the different and sometimes conflicting interests of researchers from different backgrounds.

\section{Ways of doing research digitally}

As we have pointed out, digital humanities, by means of funding schemes and renewal within teaching institutions, has brought about infrastructural change in Finland's universities and departments and facilitated collaboration with other institutions. In the following we shift focus to the meaning of $\mathrm{DH}$ for the individual researcher. Five SHH researchers, connected to HELDIG, or funded by the DH programme of the Academy of Finland, describe their approach to doing research in the digital age. Ylva Grufstedt (University of Helsinki), Risto Turunen (University of Tampere) and Tuomo Hiippala (University of Helsinki) are humanists engaged in doctoral and postdoctoral studies that bridge disciplines; Mika Pantzar (University of Helsinki) is the director of a project exploring one of the largest social-media content corpuses in Finland ${ }^{40}$; and Mikko Ojanen (University of Helsinki) is doing his doctoral research while digitising a music collection held at the Electronic Music Studio of the University of Helsinki. What is common to these diverse researchers is that digital practices and data have become integrated in a process deeply rooted in humanities and social-science research practices and traditions.

Historian Grufstedt and musicologist Ojanen have turned their recreational practices into research interests: respectively playing history videogames and composing electroacoustic music. One way of summarising how the digital nature of their resources facilitates their research is with reference to speeding up their understanding of their research subject. Ojanen admits that when he listens to music he can analyse its composition structure, but the visual representation (or spectrogram) of the digital copies from the original magnetic tapes makes this task much easier and faster. Similarly, Grufstedt's familiarity

\footnotetext{
38 On the CSC's conscious role within digital humanities, cf. https://www.csc.fi/-/csctarjoaa-palveluja-massiivisten-digitaalisten-aineistojen-kasittelyyn For example, https://rajapinta.co/association/ and https://www.facebook.com/ groups/1589981254550099/ access to the content from Suomi24, the largest online citizen's forum in Finland http://blogs.helsinki.fi/citizenmindscapes .
} 
with programming allows her to extract the games' codes and to understand "how they work the way they do". Instead of playing a game over and over, she reads in the code how the player's choices and subsequent progress are embedded in the game. In addition to conducting this digital dissection of their data so as to fully understand them, both researchers have interviewed people involved in the making and using of the data, that is, composers of electroacoustic music and instrument engineers, and videogame developers and players respectively.

Turunen and Pantzar have scaled up from the more traditional research in their deployment of digital methods. Starting with a small, qualitative sample of historical newspapers hand-written by working-class people, Turunen created a socialist vocabulary. Now he is tracing socialist ideas in the majoritarian bourgeoisie press printed in Finland between late 1771 and 1910 (Pääkkönen, Kervinen, Nivala, Kettunen, \& Mäkelä, 2016). The latter larger dataset (1 million pages) seems less familiar than the one built and analysed by "hand". Nevertheless, having learned methods from corpus linguistics ${ }^{41}$ Turunen was able to proceed in a similar manner as he did with the smaller corpus, and to identify differences in discourse, interests and thoughts between Finnish working and bourgeois classes at the turn of the 2oth century. Discourse also interests sociologist Mika Pantzar, who has been analysing social-media conversations for several years, and specifically the emotions expressed in them. He told us how important it was to obtain the metadata along with the conversations because emotions are not only in the content but also in the information about the content, such as in how quickly people react to comments. During his research he has developed an intuitive exploratory method that he calls "wandering on data", during which he explores the frequency indicators of certain keywords or semantic relations. In doing this he uses and helps to develop software with simple user interfaces ${ }^{42}$, because most SSH researchers are not learning SQL or programming, which would be another way of analysing this data.

Hiippala also uses social-media content, specifically Instagram data. Both Pantzar and Hiippala pointed out the main challenges arising from this data. Although APIs allow researchers to download social-media content directly from providers, many platforms restrict the amount drastically, and it is not possible to choose from among all the content. This makes the process of "data cleaning", or extracting the information relevant for research, laborious. As a expected by chance in a text if compared with another. 
linguist, Hiippala collaborates with geographers in the Helsinki-based Digital Geography Lab ${ }^{43}$. Even though his collaborators needed convincing, he is using multimodality to analyse a phenomenon long investigated by geographers: the extension of physical spaces to virtual ones. Hiippala's theoretical approach, multimodality, which was developed within the humanities, considers all kinds of expressions with which people communicate, in this case, the choice of language, photos, and even hashtags and emojis they attach to each post.

As is evident from these five cases, $\mathrm{DH}$ researchers are familiar with digital research resources, but they often need additional qualitative data (e.g. obtained from interviews). Furthermore, if they undertake data-driven analysis they depart from the theoretical grounds that are rooted in the humanities. These scholars benefit from the fact that $\mathrm{DH}$ research has made a promising start in Finland. On the individual level it is clear that a change from the traditional SSH research culture has started. Nevertheless, there are clearly still some major challenges to be resolved.

\section{The digital push for change}

Many of the challenges identified in the survey and the interviews with Finnish $\mathrm{DH}$ scholars, such as the difficulty in mastering big data and laborious data cleaning, are not unique to the Finnish case and reflect DH research in general. In an attempt to identify effective ways of responding to these challenges we interviewed experienced international $\mathrm{DH}$ scholars to find out how topranking DH centres had solved such problems. The reason for conducting semistructured interviews ${ }^{44}$ with active members of the selected top-ranking DH centres was to see what lessons learned we could use for further developing Finnish DH research. Given the current extensive reform of the humanities research landscape caused by the global digitalisation of knowledge production and dissemination, we had to take into account the more traditional methods used in the humanities in our discussions concerning the best ways of organising research. The everyday practices of scholars take a new direction as the digital

The Digital Geography lab is a multidisciplinary group based at the University of Helsinki https://www.helsinki.fi/en/researchgroups/digital-geography-lab

44 The main reason for carrying out these interviews was to find out what structures and practices support good $\mathrm{DH}$ research. The interviewees also provided information on how digital humanities changes the ways in which humanities research is done on the level of individual researchers and their everyday practices. The interviews were conducted in connection with the project funded by the Kone Foundation entitled "From Road Map to Roadshow - A collective demonstration \& Information project to strengthen Finnish digital history" conducted at Aalto University in 2017-2018. 
turn pushes for new ways of doing research such as via collaboration, serial digital publishing, and extending openness and accessibility into the digital realm. The new-to-humanities research practices are interrelated and call for further thinking about how an individual humanist should combine them with the old ways of doing high-quality scholarly work.

As the interviews with the Finnish DH scholars showed, high-quality DH research requires both a deep understanding of the data to be used and of the relevant literature, and the use of computer programs, programming languages and visualisation tools. The survey and the interview data revealed that the acquisition and pre-processing of data often entails extensive amounts of work. For these reasons, DH projects abroad, and also increasingly in Finland, tend to be interdisciplinary collaborative efforts rather than traditional humanist research. One could perceive the introduction of interdisciplinarity into humanities research as a tactical response to the decreasing importance of the discipline and the external neoliberal pressure to produce scholarly work (Pawlicka, 2017, p. 529). Being active in interdisciplinary research could also be considered a way of bringing humanist understanding to complex problems. The increasing potential to utilise big data in the humanities points to the global character of the phenomena and problems under study. The study of complex global issues, in which humanists' contributions are essential, also intensifies the need for interdisciplinary collaboration (Tolonen \& Lahti, 2018). A further push factor in the present-day academic world is the dependence of rewards on the number of publications. Working together comes with promises of being able to do more, and consequently to publish more.

Collaboration has not traditionally been taught to humanists, whose normal working practice has been to produce a monograph alone. Working individually is still common among DH scholars, as the above-mentioned interviews with $\mathrm{PhD}$ candidates attest. This could be connected with the fact that it makes it easier to evaluate the capabilities of the doctoral student. Nevertheless, an increasing number of $\mathrm{PhD}$ candidates, who tend to be more advanced in their research, are doing their scholarly work in interdisciplinary groups. In either case - working independently or in interdisciplinary collaboration - DH scholars need to be tech-curious and to understand at least to some degree how computers work (Jakacki \& Faull, 2016, p. 359). In both cases, too, humanists need to be specialists in their own fields, and to be able to understand and communicate with other disciplines.

Introducing a collaborative mode of working directs humanists to rethink their understanding of the social character of knowledge production, and to acknowledge its complexity. In addition, engaging in collaborative research entails discussion among project members, explicitly about the expectations 
for the project. Scholars need to explain to each other what they would consider a new and interesting finding from the perspective of their respective disciplines, and to describe how the understanding of a concept differs in the various disciplines involved in the project (Ryan Cordell, personal interview October 16, 2017; Melissa Terras, personal interview August 29, 2017). Interdisciplinary collaboration makes the researchers expert representatives of their own disciplines, which requires enhanced and explicit understanding of their own fields in comparison to the others. Researchers have to have a strong disciplinary background, and to know the methods, relevant questions and the latest findings in their field if they are to contribute to the interdisciplinary effort. Individual scholars cannot "go with the flow" and rely solely on the peer reviews and comments of their same-discipline colleagues. Alongside this strong disciplinary background, scholars working in interdisciplinary research teams must be interested in and respect the approaches of the other disciplines (Melissa Terras, personal interview August 29, 2017). Social skills are also required of scholars involved in closely collaborative projects.

Increasing collaboration increases the need for exploration, discussion and the teaching of collaborative research practices. Students in international DH centres learn about these things if they become involved in collaborative research projects (Ryan Cordell, personal interview October 16, 2017). Theorising about and teaching collaboration could also be taken one step further, there being an apparent need to draw up a chart of collaborative research projects alongside the research-process chart of an individual scholar, which would set out all the crucial steps involved in an interdisciplinary collaboration project.

Inherent in interdisciplinary collaboration is the need for a loose network of interested people, all of whom do not necessarily need to be officially affiliated with the same institution, or they could be affiliated in the larger field of GLAM (Galleries, Libraries, Archives and Museums), in industries or in non-governmental organisations (Melissa Terras, personal interview August 29, 2017). Although interdisciplinary and inter-organisational collaboration were not unknown before the digital era, the introduction of $\mathrm{DH}$ research with its call for borrowing methods, tools and data from outside the humanities strengthens the demand for collaboration across borders. The field is constantly changing, and as new methods emerge it becomes increasingly necessary to maintain interdisciplinary networks and to attend interdisciplinary events in order to learn about the new methods. This enhanced interdisciplinary aspect makes it more essential to build and maintain networks in digital humanities rather than in research based on more traditional methods.

The importance of interdisciplinary DH networks constitutes a challenge related to the institutional organisation of research, which goes beyond traditional 
departmental and institutional boundaries. Although a loose and inclusive interdisciplinary network is essential for collaboration, the institutions involved also need to engender and support continuity in long-term research expected to produce to major findings. It seems from the lessons learned abroad that $\mathrm{DH}$ organisations can be set up in various ways and can succeed. Having seen how DH has signified a renewal of relationships and structures in the universities of the Helsinki region, we find similar phenomena elsewhere. The London-based University College of London Digital Humanities Centre and the Department of Digital Humanities at King's College are structured in different ways, for example: the former has no physical premises and the latter is an established department, yet they both provide high-quality research findings. ${ }^{45}$ The main thing is that they support the continuity of the DH network.

Digital collaborative research also leads to the introduction of collaborative writing practices, and new forms of publishing research results alongside traditional articles and books. DH publications are more likely than more traditional research to be written collaboratively (Ryan Cordell, personal interview October $16,2017)$. In fact, this article was written on a shared writing platform on which the other authors were writing at the same time, which made the writing process different from the lone-rider endeavour of a sole author. When collaborative writing works well the ideas develop more quickly than when one is writing alone. Digital interdisciplinary research produces new kinds of publications, collaborative works and publication formats that favour fast, iterative, largescale research. It also generates new digital artefacts such as work flows, ontologies and interactive papers (Pawlicka, 2017, p. 531). Publishing a working pipeline, code or data-collection information alongside the text of the article contributes to the development of research (see also de Roure, 2014). Again, the introduction of collaborative writing to the humanities and the identification of new forms of knowledge are attributable not only to the advent of $\mathrm{DH}$, but also to the overall change in societies. Nevertheless, DH practices could serve as means of testing and introducing new practices in the more "traditional" corners of the humanities. The Finnish DH community should be more active in promoting the crediting of new kinds of research outputs.

Alongside the development of collaborative writing and the identification of new forms of knowledge, publishing platforms have become more varied. Complementing the "traditional" way of publishing well-polished final results of research, the digital presence of research projects and the sharing of information about them on the internet and in social media have become increasingly present in the everyday lives of humanist scholars. Both the mundane fact that 
it is easier to get funding if you are digitally present, and public-service reasons support an increasingly strong internet and social-media presence. People seek information primarily through internet-based search engines, and it is important for them to access timely and adequate research findings. The principle of UCLDH is to emphasise its digital presence on various internet and socialmedia platforms, for example. According to Terras, any digital-research facility should take its digital presence seriously (Melissa Terras, personal interview August 29, 2017). Given the increasing importance of an internet and socialmedia presence in today's world, the "traditionally trained humanist" also needs to learn new ways of disseminating results within and outside of the academic community. Although publishing in highly rated journals still matters, individual researchers, research projects and communities need to be present on the internet and in social media to spread the message of their work more widely in society. Visibility in the digital world is essential. Producing different kinds of texts including blogs, tweets and other "posts", and not only academic publications and written applications, has become an important part of everyday scholarly practice. In this process, scholarly writing is changing from "endresult reporting" increasingly towards "serial writing", meaning that an idea develops from being introduced in its raw phase in a blog post, later perhaps being improved in a platform conversation, ending up as a polished notion in a peer-reviewed publication.

The introduction of "serial writing" and publishing in different platforms is also connected to the idea of open science. Open science emphasises transparent and collaborative research practices, research data and publications that are openly available on the internet, as well as the positive effects of open and transparent research on society and academia (Eve, 2014; Open Science and Research Initiative, 2014/2017; Tolonen \& Lahti, 2018) The principles of free access to data and research findings, methodological transparency and peer reviewing are obviously not new (Lahti, Silva, Laine, Lähteenoja, \& Tolonen, 2017), and form the core of the (Western) ideal of good knowledge production. However, with digitalisation affecting the whole of society and the further democratisation of knowledge production, open science extends the old ideas of public libraries and peer-reviewing even more widely. Nowadays the ideal of the free and wide distribution of knowledge concerns not only the academic world but also the public and civil society, which are seen as having an important part in it. The principles of open science are not new in Finland, the entire educational cycle being public, and anyone has the right to enter a university lecture hall freely: they have just been updated to serve the digitalised era. Scientifically produced knowledge becomes marginal in the modern era of digitally distributed information, knowledge, opinions and even disinformation, 
if it is not available to everybody in digital from. Being openly accessible can also benefit humanist scholarship when it enables the general public to engage in peer-reviewing and discussion even during the ongoing stage of the research process. Adopting the principles of open science in research enables research collaboration and interaction with the wider society.

In terms of profiting from the benefits of openness, from the point of view of the individual researcher the introduction of open-science principles means more work, stricter requirements for planning the research process, and an expanded need for project-management skills (see also Tolonen \& Lahti, 2018). Researchers should also take into account the legal aspects of data mining, and questions related to the protection of the rights of individuals. As the survey discussed above shows, the majority of scholars would like more guidance on how to take these matters into account in their work. Keeping track and constantly updating what is going on in the research during the project, together with curating, cleaning and publishing one's data afterwards, are tasks that are essential for open science, but come in addition to the "traditional" research practices of "reading and writing". Responding to additional requirements requires collaboration.

\section{Conclusions}

The current state of digital humanities - understood both as the utilisation of computer assisted methods in humanities research, and as the exploration of the digital culture - is promising in Finland. General interest in and awareness of digital research methods and the digital culture have expanded rapidly during the past five years. There are several research projects going on in various universities that have great potential to contribute to the development of current understanding of human cultures and societies, and the digital part of it. Research infrastructures, supporting organisations and funding instruments have also been evolving. There are many features supporting the development of DH research in Finland.

Its future development nevertheless depends on how the various research and memory organisations, as well as individual scholars, succeed in joining forces. There is still strong resistance against digital humanities, and this will change only when there are enough convincing findings from $\mathrm{DH}$ research. At this point, the research still relies on borrowing methods from other disciplines, and the next step of developing methods explicitly meeting humanities needs has not yet been taken. Digital humanities will broaden the methodological toolbox of the humanities, but the primary focus of research should undoubtedly 
remain in human cultures. DH is still largely method-driven, but we hope that in the long run the prefix "digital" will disappear, and that it will become part of everyday humanities scholarship.

Although the use of more advanced computational methods will most likely become everyday practice in future SSH research, there is a definite place for digital humanities today. The emerging cultural change in the fields of humanities and social science is happening only because of the need for better digital-research practices, but also because of what it implies. Most of all, we are discussing a change from functioning as individual researchers to the establishment of research groups. This is a slow and also a painful road, especially if we aim to benchmark research groups in natural science in which collaborative work does not mean writing an anthology together, it means that different fields of scholarship join forces. This is the path to the difficult area between sciences in which new things happen (Svensson, 2015). We believe it is the road that needs to be trodden in digital humanities in Finland. Moreover, in light of the evidence from our survey of digital practices in Finland, the main aim should not be to re-train individual SSH researchers so that their traditional skills are complemented with the ability to write code. The emphasis should rather be on genuine collaboration between different fields of science in which the most crucial issue is to enable humanists and data scientists to speak the same language. It is also evident that the transformation from individual researchers to research groups in SSH research cannot happen without considerable infrastructural support, changes in teaching, and the implementation and realisation of the relevance of open science.

There is a need to engage in more open discussion about the new best ways of conducting humanities research in the increasingly digitised world. The ways and the directions in which $\mathrm{DH}$ develops will not merely affect the state of DH in the future, but will also influence the future direction of humanities research in general in increasingly digital societies. Experiences with digital humanities, as a forerunner in digital matters, may help to ease this transformation in the more traditional corners of the humanities.

\section{References}

Ahnert, R., \& Ahnert, S. E. (2015). Protestant letter networks in the reign of Mary I: a quantitative approach. ELH, 82(1), 1-33. https://doi.org/10.1353/elh.2015.0000

Allen, T., Cooney, C., Douard, S., Horton, R., Morissey, R., Olsen, M., ... Voyer, R. (2010). Plundering philosophers: identifying sources of the encyclopédie. Journal of the Association for History and Computing, 13(1). http://hdl. handle. net/2027/spo.3310410.0013.107 
Bassett, C. (2015). Plenty as a response to austerity? Big data expertise, cultures and communities. European Journal of Cultural Studies, 18(4-5), 548-563. https://doi.org/10.1177/ 1367549415577394

Berry, D. M. (2014). Post-digital humanities: computation and cultural critique in the arts and humanities. Educause, 49, 22-26. http://sro.sussex.ac.uk/id/eprint/49324

Dallas, C., Chatzidiakou, N., Benardou, A., Bender, M., Berra, A., Clivaz, C., ... Zebec, T. (2017). European survey on scholarly practices and digital needs in the arts and humanities - highlights report. Zenodo. https://doi.org/10.5281/zenodo. 260101

de Roure, D. (2014). The future of scholarly communications. Insights, 27(3). https://doi.org/ 10.1629/2048-7754.171

Eve, M. P. (2014). Open access and the humanities: contexts, controversies and the future. Cambridge: Cambridge University Press.

Hankamäki, J. (2017). Kun yliopistolla keksittiin digitaalikello - "digitaalisten ihmistieteiden" tarkastelua. Tieteessä Tapahtuu, 35(1). https://journal.fi/tt/article/view/60794

Haverinen, A., \& Suominen, J. (2015). Koodaamisen ja kirjoittamisen vuoropuhelu? - mitä on digitaalinen humanistinen tutkimus. Ennen Ja Nyt, (19.2.2015). http://www. ennenjanyt. net/2015/02/koodaamisen-ja-kirjoittamisen-vuoropuhelumita-on-digitaalinen-humanistinen-tutkimus/

Hyvönen, E. (2017). Digitaalisten ihmistieteiden keskus HELDIG käynnisti toimintansa. Tieteessä Tapahtuu, 35(2). https://journal.fi/tt/article/view/62348

Jakacki, D., \& Faull, K. (2016). Doing DH in the classroom. Transforming the humanities curriculum through digital engagement. In C. Crompton, R. J. Lane, \& R. G. Siemens (eds.), Doing digital humanities: Practice, training, research. Taylor \& Francis.

Järvinen, A. (ed.). (1999). Johdatus digitaaliseen kulttuuriin. Tampere: Vastapaino.

Lahti, L., Silva, F. da, Laine, M., Lähteenoja, V., \& Tolonen, M. (2017). Alchemy \& algorithms: perspectives on the philosophy and history of open science. Research Ideas and Outcomes, 3. https://doi.org/10.3897/rio.3.e13593

Leca-Tsiomis, M. (2013). The use and abuse of the digital humanities in the history of ideas: how to study the encyclopédie. History of European Ideas, 39(4), 467-476. https://doi.org/10. 1080/01916599.2013.774115

Matres, I. (2016). Report on the DARIAH digital practices in the arts and humanities web survey 2016. DARIAH Digital Methods and Practices Observatory Working Group (DiMPO). https://www.helsinki.fi/sites/default/files/atoms/files/dariah_web_survey_chapter_ finland.pdf

Mustajoki, A. (2017). Digitaalisia ihmistieteitä tarvitaan. Tieteessä Tapahtuu, 35(2). https:// journal.fi/tt/article/view/62530

Open Science and Research Initiative. (2014/2017). The Handbook of Open Science and Research. Open Science; Research Initiative (ATT). https://avointiede.fi/www-kasikirja

Paju, P. (2016). Raportti digitaalisen historiantutkimuksen kyselyvastauksista. Towards a roadmap for digital history in finland: Mapping the past, present \& future. https://digihistfinlandroadmapblog.files.wordpress.com/2016/09/digitaalinenhistoriantutkimus-kyselytuloksia5.pdf

Pawlicka, U. (2017). Data, collaboration, laboratory: bringing concepts from science into humanities practice. English Studies, 98(5), 526-541. https://doi.org/10.1080/0013838X. 2017.1332022

Päkkkönen, T., Kervinen, J., Nivala, A., Kettunen, K., \& Mäkelä, E. (2016). Exporting Finnish digitized historical newspaper contents for offline use. D-Lib Magazine, 22(7/8). https:// doi.org/10.1045/july2016-paakkonen 
Puhl, J., Andorfer, P., Höckendorff, M., Schmunk, S., Stiller, J., \& Thoden, K. (2015). Diskussion und definition eines research data lifecycle für die digitalen geisteswissenschaften (No. 11) (p. 51). Göttingen: DARIAH-DE. http://nbn-resolving.de/urn:nbn:de:gbv:7-dariah-2015-44

Sinnemäki, K., \& Tolonen, M. (2015). Digitaaliset ihmistieteet tutkimuskartalle. Tieteessä Tapahtuu, 33(4). https://journal.fi/tt/article/view/51172

Sula, C. A. (2013). Digital humanities and libraries: a conceptual model. Journal of Library Administration, 53(1), 10-26. https://doi.org/10.1080/01930826.2013.756680

Suominen, J. (2013). Kieltäydyn määrittelemästä digitaalista kulttuuria - eli miten muuttuvalle tutkimuskohteelle ja tieteenalalle luodaan jatkuvuutta. WiderScreen, 15(2-3). http://widerscreen.fi/numerot/2013-2-3/kieltaydyn-maarittelemasta-digitaalistakulttuuria/

Svensson, P. (2015). The Humanistiscope: exploring the situatedness of humanities infrastructure. In P. Svensson \& D. T. Goldberg (eds.), Between humanities and the digital (pp. 337-354). MIT Press.

Tolonen, M., \& Lahti, L. (2018). Digitaaliset ihmistieteet (Digital Humanities) ja historiantutkimus. In M. Hannikainen, M. Danielsbacka, \& T. Teropa (eds.), Menneisyyden rakentajat: Teoriat historiantutkimuksessa (pp. 235-258). Helsinki: Gaudeamus. 